\title{
Tissue Plasminogen Activator Promotes Platelet Disaggregation in Plasma
}

\author{
Joseph Loscalzo and Douglas E. Vaughan \\ Divisions of Vascular Medicine and Cardiology, Brigham and Women's Hospital and \\ Harvard Medical School, Boston, Massachusetts 02115
}

\begin{abstract}
We studied the disaggregation of human platelets by tissue-type plasminogen activator (t-PA). When added to a suspension of human platelets induced to aggregate in plasma with adenosine 5'-diphosphate, t-PA promoted disaggregation of platelets over several minutes. Addition of fresh plasma or purified human fibrinogen to disaggregated platelets facilitated (reversible) aggregation and subsequent disaggregation. Aspirin treatment of platelets markedly potentiated the ability of t-PA to induce disaggregation. Disaggregation was inhibited by alpha-2-antiplasmin. Comparative analysis of the rate of proteolysis of plateletbound fibrinogen with that of ambient plasma fibrinogen suggested that fibrinogenolysis of cohesive fibrinogen occurred more rapidly than fibrinogenolysis of ambient fibrinogen. These data demonstrate that $\mathbf{t}-\mathbf{P A}$ facilitates platelet disaggregation in plasma through kinetically selective proteolysis of cohesive fibrinogen by plasmin, and suggest that thrombolytic mechanisms may serve both to remove platelets from platelet-fibrin thrombi and to disperse circulating platelet aggregates.
\end{abstract}

\section{Introduction}

Tissue-type plasminogen activator (t-PA) ${ }^{1}$ has been intensively studied in recent years as an endogenous biomolecule that is important for initiating fibrinolysis (1-5). Plasminogen activation by endogenous t-PA occurs specifically at sites of thrombus formation and fibrin itself enhances this activation (6). Platelets have also recently been shown to provide a surface that enhances t-PA-induced plasminogen activation (7). Once generated, plasmin not only catalyzes fibrinolysis but also modifies the platelet surface, inhibiting platelet aggregation $(8,9)$. In that thrombi are composed of fibrin and platelets, and that both the fibrin polymer and platelet surface promote t-PA-mediated plasminogen activation, these mechanisms of plasminogen activation serve to confine plasmin production and action to the thrombus.

While modification of platelets by plasmin inhibits aggregation in vitro, the importance of this mechanism in vivo has not been established. Furthermore, since fibrinogen, an alternative substrate for plasmin, is important in maintaining cohesion among platelets induced to aggregate by a variety of agonists,

Address reprint requests to Dr. Loscalzo, Department of Medicine, Brigham and Women's Hospital, 75 Francis St., Boston, MA 02115. 1987.

Received for publication 31 July 1986 and in revised form 28 January

1. Abbreviations used in this paper: GPRP, glycyl-L-prolyl-L-arginyl-Lproline; t-PA, tissue-type plasminogen activator.

J. Clin. Invest.

(c) The American Society for Clinical Investigation, Inc.

0021-9738/87/06/1749/07 \$1.00

Volume 79, June 1987, 1749-1755 local promotion of plasmin production at the platelet surface $(7,10)$ may also be important in promoting disaggregation of platelet aggregates as well as inhibiting aggregate formation. Since platelet aggregates have been implicated in the pathogenesis of many clinically important ischemic vascular events (11-15), their disaggregation may be a relevant protective mechanism in vivo. For these reasons, we examined the effect of recombinant t-PA on platelet aggregates produced in vitro in platelet-rich plasma. Our results demonstrate that t-PA promotes platelet disaggregation in plasma and that its does so through proteolysis of cohesive fibrinogen by plasmin.

\section{Methods}

Materials. Adenosine 5'-diphosphate (ADP), aprotinin, hirudin, and glycyl-L-prolyl-L-arginyl-L-proline (GPRP) were purchased from Sigma Chemical Co., St. Louis, MO. Human fibrinogen, plasmin, plasminogen, streptokinase, and H-D-valyl-L-leucyl-L-lysine-p-nitroanilide dihydrochloride (S-2251) and H-D-isoleucyl-L-prolyl-L-arginyl-p-nitroanilide dihydrochloride (S-2288) were obtained from KABI Diagnostics through Helena Laboratories, Beaumont, TX. Calf skin collagen was purchased from Cooper Biomedical, Inc., Malvern, PA. Plasminogen-free bovine thrombin was purchased from Miles Pharmaceuticals, Naperville, IL. Human alpha-2-antiplasmin was obtained from American Diagnostica, Inc., Greenwich, CT. Recombinant human t-PA was kindly provided by Genentech, Inc., South San Francisco, CA. Na[ $\left.{ }^{125} \mathrm{I}\right]$ and $\mathrm{Na}\left[{ }^{131} \mathrm{I}\right]$ were obtained from New England Nuclear, Boston, MA. Sepharose 2B was purchased from Pharmacia Fine Chemicals, Inc., Uppsala, Sweden. Iodobeads were obtained from Pierce Chemical Co., Rockford, IL.

Collection and preparation of human platelets. Venous blood was anticoagulated with $13 \mathrm{mM}$ trisodium citrate. Platelet-rich plasma was prepared by centrifugation at $120 \mathrm{~g}$ for $10 \mathrm{~min}$ at $22^{\circ} \mathrm{C}$. The top twothirds of the platelet-rich plasma was removed for aggregation experiments. Platelet counts were determined with a counter equipped with a 50- $\mu \mathrm{m}$ aperture (model ZM; Coulter Electronics Inc., Hialeah, FL). Platelets were kept at $22^{\circ} \mathrm{C}$ for up to $1 \mathrm{~h}$ before use. Platelets were treated with aspirin by incubation for $30 \mathrm{~min}$ with $1 \mathrm{mM}$ aspirin at $25^{\circ} \mathrm{C}$ in platelet-rich plasma. Washed platelets were obtained by centrifuging platelets from platelet-rich plasma at $800 \mathrm{~g}$ for $20 \mathrm{~min}$, resuspending the platelets in platelet washing buffer $(10 \mathrm{mM}$ triosodium citrate, $0.15 \mathrm{M}$

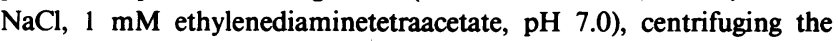
platelets at $800 \mathrm{~g}$ for $20 \mathrm{~min}$, repeating the suspension in washing buffer and centrifugation, and finally suspending the platelets at $3.0 \times 10^{8} / \mathrm{ml}$ in modified Tyrode's solution $(0.13 \mathrm{M} \mathrm{NaCl}, 2.7 \mathrm{mM} \mathrm{KCl}, 12 \mathrm{mM}$ $\mathrm{NaHCO}_{3}, 0.42 \mathrm{mM} \mathrm{NaH}_{2} \mathrm{PO}_{4}, \mathrm{pH} 7.4,1.0 \%$ bovine serum albumin).

Platelet aggregation. Platelets in platelet-rich plasma were typically suspended at a final concentration of $3.0 \times 10^{8} / \mathrm{ml}$ and aggregated with 1.5 or $11 \mu \mathrm{M}$ ADP, with $0.5 \mathrm{U} / \mathrm{ml}$ plasminogen-free bovine thrombin in the presence of $1 \mathrm{mM}$ GPRP, or with $0.12 \mathrm{mg} / \mathrm{ml}$ calf skin collagen. Aggregation (16) was monitored at $37^{\circ} \mathrm{C}$ with stirring at $900 \mathrm{rpm}$ using a dual-channel aggregometer (Payton Assoc., Inc., Buffalo, NY).

Platelet disaggregation. Disaggregation of platelets in platelet-rich plasma was induced by addition of t-PA after the aggregation response reached its maximum. Disaggregation was quantitated by measuring either $(a)$ the extent of reduction in light transmittance or $(b)$ the maximal rate of decrease in light transmittance after addition of t-PA (in percent transmittance per second). 
- Platelet radioiodination. Surface proteins of intact platelets were labeled with ${ }^{125}$ I using lactoperoxidase $(17,18)$. The labeled platelets were suspended in fresh platelet-poor plasma for aggregation and disaggregation experiments. Fresh platelets had a sp act of $1.5 \times 10^{7} \mathrm{cpm} / 10^{9}$ platelets.

Fibrinogen purification. Fibrinogen was purified according to the method of Bennett and Vilaire (19). Purified fibrinogen was found to be $98 \%$ clottable and to contain $<1.5 \mu \mathrm{g}$ of fibronectin per $100 \mu \mathrm{g}$ of protein and $<1.0 \mu \mathrm{g}$ of von Willebrand factor per $100 \mu \mathrm{g}$ of protein as determined by solid-phase immunoassays using immunoadsorbed polyclonal rabbit anti-human fibronectin and von Willebrand factor antisera, respectively (20). The purified fibrinogen was also found to contain $<0.2 \mu \mathrm{g}$ thrombospondin per $100 \mu \mathrm{g}$ of protein as measured in a radioimmunoassay performed by Dr. Henry Slayter, Dana Farber Cancer Institute, Boston, MA.

Fibrinogen radioiodination. Purified fibrinogen was radioiodinated using Iodo-beads and had a sp act of $0.1-0.2 \mu \mathrm{Ci} / \mu \mathrm{g}$.

Fibrinogen binding assay. Platelets freshly isolated from platelet-rich plasma or disaggregated by t-PA in plasma were washed twice with platelet washing buffer and analyzed for ADP-stimulated fibrinogen binding according to the method of Bennett and Vilaire (19) and others (21) at $25^{\circ} \mathrm{C}$. Nonspecific binding was distinguished from specific binding by addition of a 50-fold excess of cold fibrinogen. Platelet-bound fibrinogen was separated from free fibrinogen by centrifuging the platelets through a $20 \%$ sucrose cushion at $8,700 \mathrm{~g}$ for $2.5 \mathrm{~min}$.

Analytical methods. Plasma fibrinogen was measured by the method of Rampling and Gaffney (22) using $250 \mathrm{U} / \mathrm{ml}$ aprotinin to inhibit plasmin immediately before sulphite precipitation. Fibrinogen/fibrin degradation products were determined by the method of Merskey and colleagues $(23,24)$. Plasmin activity was measured using the chromogenic substrate S-2251 $(25,26)$. Sodium dodecyl sulfate-polyacrylamide gel electrophoresis was performed according to the method of Laemmli (27) using $7.5 \%$ slab gels. Autoradiograms of the dried gels were produced by exposing x-ray film (Eastman Kodak Co., Rochester, NY) to the gels at $-20^{\circ} \mathrm{C}$. Protein determinations were performed according to the method of Lowry and colleagues (28).

\section{Results}

Disaggregation of platelets in platelet-rich plasma by $t-P A$. The addition of purified t-P.A to a suspension of aggregated platelets in platelet-rich plasma produced a rapid decrease in light transmittance indicative of disaggregation (Fig. 1). The rate of dis-

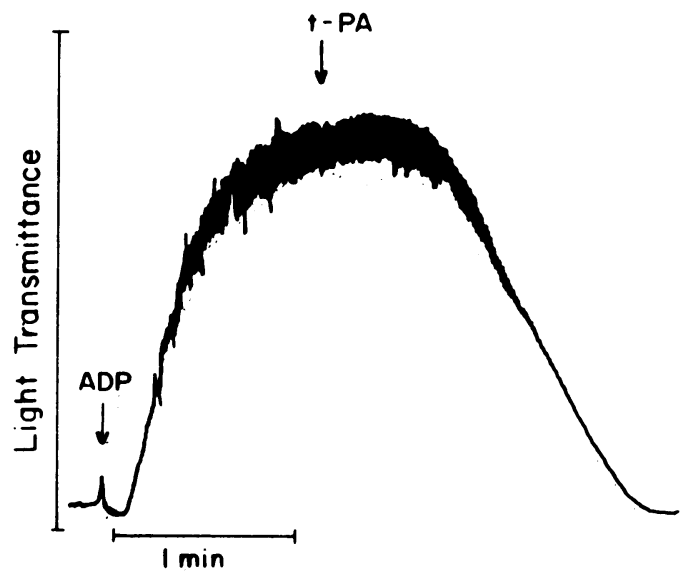

Figure 1. Disaggregation of platelets in plasma by t-PA. Platelets were induced to aggregate by addition of $11 \mu \mathrm{M}$ ADP, and at $1 \mathrm{~min}$ after addition of the agonist t-PA was added to a final concentration of 96 $\mu \mathrm{g} / \mathrm{ml}$. Platelets were stirred throughout the experiment at $900 \mathrm{rpm}$ in plasma at $37^{\circ} \mathrm{C}$. aggregation and its extent were dependent on the concentration of t-PA as well as the time of its addition. Higher concentrations of t-PA produced faster rates of disaggregation and greater extents of change in light transmittance (Fig. 2). In addition, the earlier t-PA was added after ADP, the faster the rate of disaggregation and the greater its extent (Fig. 3).

Reversibility of disaggregation. Once disaggregated, platelets appeared normally discoid in shape by phase-contrast microscopy. Resuspension of these platelets in fresh platelet-poor plasma supported another cycle of aggregation and disaggregation (Fig. 4). In this experiment, platelets were induced to aggregate with $11 \mu \mathrm{M}$ ADP in platelet-rich plasma and $96 \mu \mathrm{g} / \mathrm{ml} \mathrm{t}-\mathrm{PA}$ was added $1 \mathrm{~min}$ after addition of ADP. The disaggregated platelets were collected by centrifugation at $800 \mathrm{~g}$ for $10 \mathrm{~min}$ at $25^{\circ} \mathrm{C}$, resuspended in fresh platelet-poor plasma from the same donor, and subjected to a second cycle of aggregation and disaggregation using the same concentrations of ADP and t-PA, respectively. Restoration of aggregation was also accomplished by adding 1 $\mathrm{mg} / \mathrm{ml}$ purified human fibrinogen instead of platelet-poor plasma to the disaggregated platelets.

Inhibition of disaggregation by alpha-2-antiplasmin. Preincubation of platelet-rich plasma with a 1.3-fold molar excess of alpha-2-antiplasmin $(15 \mu \mathrm{M})$ over plasmin before addition of ADP completely inhibited disaggregation by t-PA, even at t-PA concentrations as high as $96 \mu \mathrm{g} / \mathrm{ml}$. This concentration of alpha2-antiplasmin did not inhibit the activity of t-PA against the chromogenic substrate, S-2288. These data indicate that the

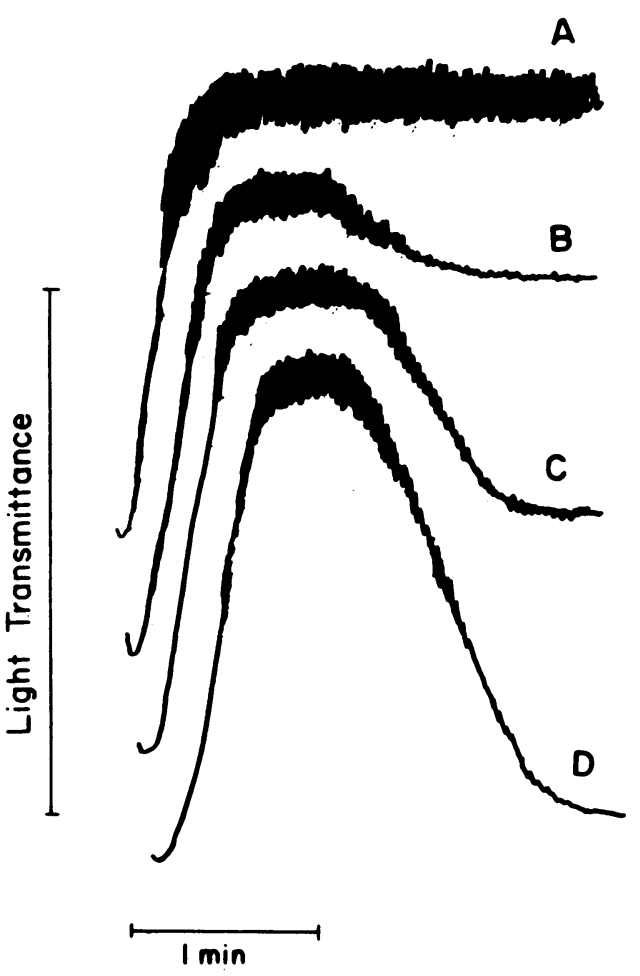

Figure 2. Effect of t-PA concentration on platelet disaggregation. Platelets were induced to aggregate by addition of $11 \mu \mathrm{M}$ ADP, and at $1 \mathrm{~min}$ after addition of the agonist t-PA was added to a final concentration of (A) $0.32 \mu \mathrm{g} / \mathrm{ml}$, (B) $5.0 \mu \mathrm{g} / \mathrm{ml}$, (C) $48.0 \mu \mathrm{g} / \mathrm{ml}$, and (D) 96.0 $\mu \mathrm{g} / \mathrm{ml}$. Platelets were stirred throughout the experiment at $900 \mathrm{rpm}$ in plasma at $37^{\circ} \mathrm{C}$. 


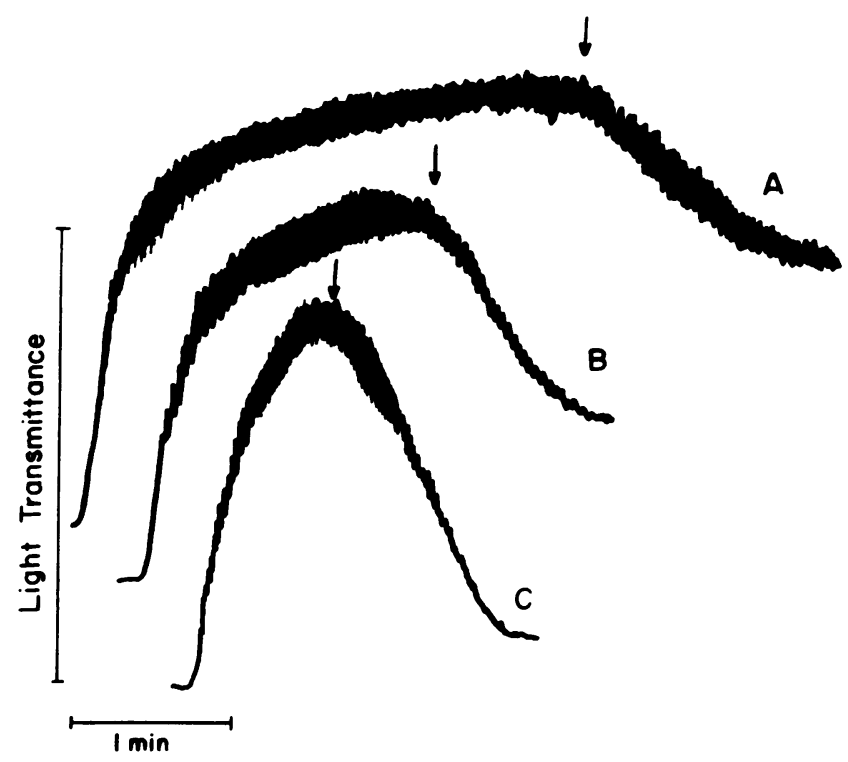

Figure 3. Effect of time of addition of t-PA on platelet disaggregation. Platelets were induced to aggregate by addition of $11 \mu \mathrm{M}$ ADP, and at (A) $3.4 \mathrm{~min}$, (B) $2.0 \mathrm{~min}$, and (C) $1.0 \mathrm{~min}$ after addition of the agonist $96 \mu \mathrm{g} / \mathrm{ml} \mathrm{t}-\mathrm{PA}$ was added. Platelets were stirred throughout the experiment at $900 \mathrm{rpm}$ in plasma at $37^{\circ} \mathrm{C}$.

proteolytic effect of plasmin, and not the amidolytic effect of tPA itself, is likely responsible for platelet disaggregation.

Potentiation of $t$-PA-induced disaggregation by aspirin. Treating platelets with aspirin in platelet-rich plasma enhanced markedly the rate of disaggregation over a wide range of t-PA concentrations (Fig. 5). The $\mathrm{EC}_{50}$ for t-PA decreased by approximately two orders of magnitude (to $\sim 5 \mu \mathrm{g} / \mathrm{ml}$ ) with platelets treated with aspirin compared with untreated platelets. Importantly, some disaggregation was detected even without aspirin treatment at concentrations of t-PA as low as $5 \mu \mathrm{g} / \mathrm{ml}$, a pharmacologically achievable concentration (29), and at concentrations of t-PA as low as $0.5 \mu \mathrm{g} / \mathrm{ml}$ with aspirin treatment.

Disaggregation of washed platelets by $t-P A$. The addition of $17 \mu \mathrm{g} / \mathrm{ml}$ of $\mathrm{t}-\mathrm{PA}$ to a suspension of washed platelets induced to aggregate with $11 \mu \mathrm{M}$ ADP in modified Tyrode's solution containing $0.05 \mathrm{mg} / \mathrm{ml}$ purified human plasminogen and $1 \mathrm{mg}$ / $\mathrm{ml}$ human fibrinogen produced a rapid decline in light transmittance which was indicative of disaggregation $\left(t_{1 / 2}=9.5 \pm 1.2\right.$ min, $n=3$ ). Aggregation was restored by addition of purified fibrinogen (to $1 \mathrm{mg} / \mathrm{ml}$ ) in this washed system as well.

Lack of effect of $t-P A$ on platelet surface glycoproteins. To assess the effect of plasminogen activation on platelets in plateletrich plasma, radioiodinated freshly obtained platelets were resuspended in fresh platelet-poor plasma at a final concentration of $2 \times 10^{8} / \mathrm{ml}$. The platelets were aggregated with $11 \mu \mathrm{M}$ ADP and disaggregation induced with $48 \mu \mathrm{g} / \mathrm{ml}$ t-PA. After incubating the aggregates with $\mathrm{t}-\mathrm{PA}$ at $37^{\circ} \mathrm{C}$ for $30 \mathrm{~min}$, the platelets were collected by centrifugation at $800 \mathrm{~g}$ for $10 \mathrm{~min}$, solubilized with a sodium dodecyl sulfate-containing polyacrylamide gel sample buffer, and the solubilized platelet pellets subjected to sodium dodecyl sulfate-polyacrylamide gel electrophoresis. Autoradiography of the gel demonstrated no change in the the intensity of the glycoprotein IIb/IIIa or glycoprotein Ib bands compared with control platelets not exposed to t-PA.

To prove further that t-PA had no significant effect on fibrinogen binding to platelets, direct binding experiments were performed using purified radioiodinated fibrinogen. Platelets were either freshly isolated from platelet-rich plasma for use in binding assays, or were obtained from platelet-rich plasma in which they were aggregated with $11 \mu \mathrm{M}$ ADP then disaggregated with $96 \mu \mathrm{g} / \mathrm{ml} \mathrm{t}$-PA. These disaggregated platelets were obtained $2 \mathrm{~min}$ after addition of the $\mathrm{t}-\mathrm{PA}$, at which time $250 \mathrm{U} / \mathrm{ml}$ aprotinin was added to inhibit further plasmin action. Platelets were then washed twice in platelet washing buffer and fibrinogen binding measured according to standard published methods (19, 21) at $25^{\circ} \mathrm{C}$ in modified Tyrode's buffer, $\mathrm{pH} 7.4$, containing 3.5 $\mathrm{mg} / \mathrm{ml}$ bovine serum albumin, $5.5 \mathrm{mM}$ glucose, $0.5 \mathrm{mM} \mathrm{CaCl}$, and $10 \mu \mathrm{M}$ ADP. The results of these experiments are shown in Table I and indicate that both freshly obtained platelets and disaggregated platelets bound fibrinogen similarly. Two classes of binding sites were found in both cases. Freshly obtained platelets bound $\sim 1,500$ molecules of fibrinogen per platelet with a dissociation constant $\left(K_{d}\right)$ of $\sim 0.90 \times 10^{-7} \mathrm{M}$ and $\sim 55,000$ molecules per platelet with a $K_{\mathrm{d}}$ of $\sim 2.0 \times 10^{-7} \mathrm{M}$; disaggregated platelets bound $\sim 1,400$ molecules of fibrinogen per platelet with a $K_{\mathrm{d}}$ of $\sim 0.95 \times 10^{-7} \mathrm{M}$ and $\sim 53,000$ molecules of $\mathrm{fi}$ brinogen per platelet with a $K_{d}$ of $\sim 2.3 \times 10^{-7} \mathrm{M}$. Data analyses were performed according to the method of Scatchard (30) and the data fitted to the best curve according to the method of Rodbard (31).

Lack of effect of fibrinogen degradation products on platelet aggregates. To assess the effects of fibrinogen degradation products on aggregated platelets, platelet-poor plasma was treated with either $(a) 2 \mathrm{U} / \mathrm{ml}$ of plasminogen-free bovine thrombin at $25^{\circ} \mathrm{C}$ for $30 \mathrm{~min}$, which produced $250 \mu \mathrm{g} / \mathrm{ml}$ of fibrinogen degradation products, after which thrombin was inhibited with 5 $\mathrm{U} / \mathrm{ml}$ hirudin; or (b) $20 \mu \mathrm{g} / \mathrm{ml} \mathrm{t}-\mathrm{PA}$ at $37^{\circ} \mathrm{C}$ for $20 \mathrm{~min}$, which produced $400 \mu \mathrm{g} / \mathrm{ml}$ of fibrinogen degradation products, after

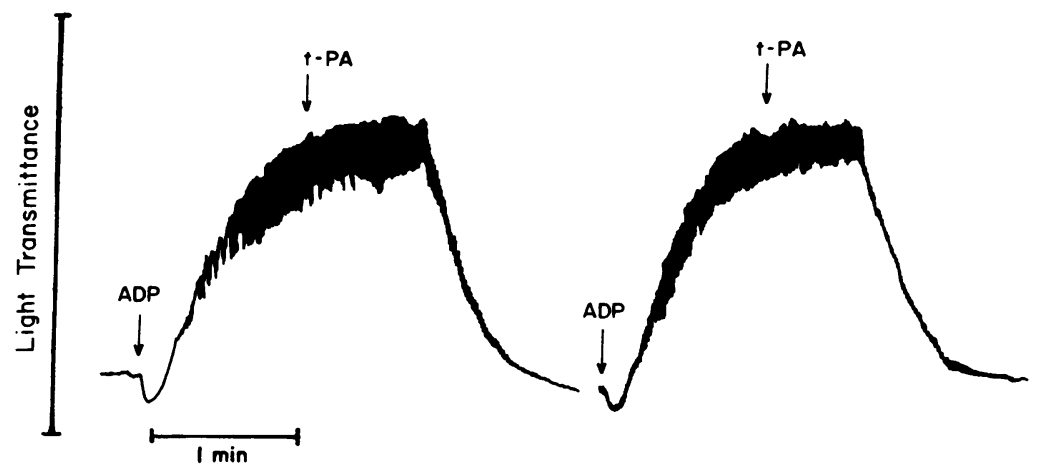

Figure 4. Reversibility of platelet disaggregation in plasma by t-PA. Platelets were induced to aggregate with $11 \mu \mathrm{M}$ ADP and disaggregated at $1 \mathrm{~min}$ by addition of $96 \mu \mathrm{g} / \mathrm{ml} \mathrm{t}-\mathrm{PA}$. The disaggregated platelets were resuspended in fresh plasma and the cycle of aggregation and disaggregation repeated, as described in Results. 


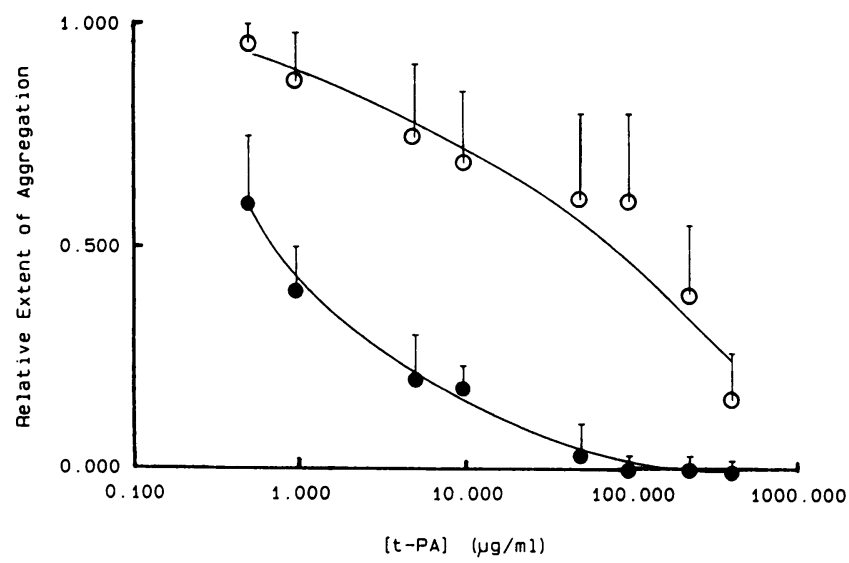

Figure 5. Effects of aspirin on platelet disaggregation by t-PA. The relative extent of aggregation remaining at the end of $5 \mathrm{~min}$ after addition of increasing concentrations of t-PA is plotted for platelets in plasma (0) and for aspirin-treated platelets in plasma (๑). Each point represents the mean \pm standard deviation of three experiments using three different donors, each done in duplicate.

which the plasmin was inhibited by $250 \mathrm{U} / \mathrm{ml}$ aprotinin. $100 \mu \mathrm{l}$ of either of these fibrinogen degradation product-containing plasmas was then added to $400 \mu$ l of stirred platelet-rich plasma at $37^{\circ} \mathrm{C}$ in which the platelets had been induced to aggregate with $11 \mu \mathrm{M}$ ADP. No disaggregation was observed after $20 \mathrm{~min}$ for plasma containing either type of fibrinogen degradation product.

Differential effect of addition of $t-P A$ to platelet-rich plasma on free fibrinogen and platelet-bound fibrinogen. Platelets in platelet-rich plasma to which was added $2,000 \mathrm{cpm} / \mu 1$ of ${ }^{125} \mathrm{I}$ fibrinogen (100 $\mu \mathrm{l}$ of ${ }^{125}$ I-fibrinogen $/ 1.4 \mathrm{ml}$ of platelet-rich plasma) were induced to aggregate with $11 \mu \mathrm{M}$ ADP or $0.5 \mathrm{U} /$ $\mathrm{ml}$ plasminogen-free bovine thrombin in the presence of $1 \mathrm{mM}$ GPRP at $37^{\circ} \mathrm{C}$ with stirring at $900 \mathrm{rpm}$ for $1 \mathrm{~min}$, after which the platelet aggregates were allowed to settle under unit gravity $(1 \mathrm{~g})$ at room temperature. These aggregates were then resuspended in fresh plasma, allowed to settle, and resuspended again

Table I. Effect of T-PA Treatment of Platelets on Fibrinogen Binding

\begin{tabular}{lcl}
\hline & Number of sites & $K_{\mathrm{d}}$ \\
\hline & molecules per platelet & $M \times 10^{7}$ \\
Washed platelets* $^{*}$ & 1,500 & 0.90 \\
Disaggregated platelets $^{\ddagger}$ & 55,000 & 2.0 \\
& 1,400 & 0.95 \\
& 53,000 & 2.3 \\
\hline
\end{tabular}

* Platelets were obtained from citrate-treated whole blood and prepared as described in Methods and Results. Each point represents the average of two experiments performed in duplicate. Numbers of sites and $K_{d} \mathrm{~s}$ were derived from Scatchard plots of the binding data (30) analyzed according to the methods of Rodbard (31).

${ }^{\ddagger}$ Disaggregated platelets were obtained as described in Methods and Results and prepared as described. Each point represents the average of two experiments performed in duplicate. Numbers of sites and $K_{d} s$ were derived from Scatchard plots of the binding data (30) analyzed according to the methods of Rodbard (31). in fresh plasma, all at room temperature without stirring within $2 \mathrm{~min}$. After the final resuspension, $500 \mathrm{cpm} / \mu$ l of ${ }^{131} \mathrm{I}$-fibrinogen was added ( $25 \mu \mathrm{l} \mathrm{of}{ }^{131} \mathrm{I}$-fibrinogen/1.4 $\mathrm{ml}$ of suspended platelets), the total ${ }^{125}$ I-fibrinogen and ${ }^{131}$ I-fibrinogen measured, and t-PA was added to $96 \mu \mathrm{g} / \mathrm{ml}$. Aliquots of the suspension were removed at various times at sites peripheral to the stirring vortex, platelets were sedimented at $8,000 \mathrm{~g}$ for $30 \mathrm{~s}$, and ${ }^{125} \mathrm{I}$-fibrinogen released from the platelet aggregate measured by counting the radioactivity in the supernatant. ${ }^{131}$ I-Fibrinogen was measured by sulphite precipitation of the supernatant and resolubilization of the precipitated fibrinogen using $\mathrm{NaOH}$ and urea, as described by Rampling and Gaffney (22). From these data, the rate of loss of platelet-bound radioiodinated fibrinogen and the rate of proteolysis of ambient plasma fibrinogen were determined. The rate of disaggregation of platelets was also measured. Each of these processes obeyed simple first-order kinetics, the time points defining a straight line on semilogarithmic plots as a function of time. Using ADP as the agonist, the $t_{1 / 2}$ for disaggregation was $2.3 \mathrm{~min}$, the $t_{1 / 2}$ for loss of platelet-bound fibrinogen was 2.6 min, and the $t_{1 / 2}$ for ambient plasma fibrinogenolysis was $\mathbf{8 . 2}$ min. With thrombin as the agonist, the $t_{1 / 2}$ for disaggregation was $1.6 \mathrm{~min}$, the $t_{1 / 2}$ for loss of platelet-bound fibrinogen was $1.9 \mathrm{~min}$, and the $t_{1 / 2}$ for ambient plasma fibrinogenolysis was $7.0 \mathrm{~min}$. Each of these processes obeyed simple first-order kinetics. In the simplest approach to these data, one might speculate that these rates indicate that disaggregation correlates best with the rate of proteolysis of cohesive fibrinogen; however, because of the complexity of the cellular events determining the shape of the aggregation curve, such a simplistic analysis is probably not justified. What can be concluded from these data with certainty, however, is that the rate of proteolysis of cohesive fibrinogen is significantly faster than that of ambient fibrinogen. Once dissociated from the platelet, radioiodinated fibrinogen was not sulphite precipitable, which suggests that loss of platelet-bound fibrinogen occurred as a consequence of kinetically selective fibrinogenolysis at the platelet surface. In the absence of significant proteolysis of the platelet fibrinogen receptor, these data suggest that fibrinogenolysis of platelet-bound fibrinogen is chiefly responsible for platelet disaggregation by t-PA-activated plasminogen in plasma.

Effect of $t-P A$ on platelet aggregation induced by thrombin and collagen. Platelets induced to aggregate with $0.5 \mathrm{U} / \mathrm{ml}$ thrombin in the presence of GPRP (to prevent fibrin polymerization) did disaggregate in response to t-PA (Table II). Platelets induced to aggregate with $0.12 \mathrm{mg} / \mathrm{ml}$ calf skin collagen, however, were not disaggregable by t-PA (Table II).

\section{Discussion}

Many authors have considered the importance of circulating platelet aggregates in the pathogenesis of clinically significant atherogenic and thrombogenic phenomena (11, 12, 15, 32-35). The evidence for the presence of circulating aggregates has, however, been the subject of some controversy, primarily because the methods used for quantitating platelet aggregates may induce their formation (35-39). Nevertheless, the best of pathologic data $(11,12,15)$ support the contention that platelet aggregates are important in the pathogenesis of ischemic vascular events.

We have shown that t-PA added to platelet aggregates formed in vitro in plasma promotes disaggregation. While much evidence indicates that exposure of resting platelets to plasmin inhibits aggregation $(8,9)$, only one report indicates that exposing platelet 
Table II. Rates of Platelet Disaggregation by T-PA

\begin{tabular}{|c|c|c|c|c|c|}
\hline \multirow[b]{2}{*}{ Agonist } & \multicolumn{5}{|c|}{$[\mathrm{t}-\mathrm{PA}](\mu \mathrm{g} / \mathrm{ml})$} \\
\hline & 2.5 & 6.0 & 17.0 & 48.0 & 96.0 \\
\hline & $t_{1 / 2}(\min )$ & $t_{1 / 2}(\min )$ & $t_{1 / 2}(\min )$ & $t_{1 / 2}(\min )$ & $t_{1 / 2}(\min )$ \\
\hline Thrombin* & $6.9 \pm 2.1$ & $4.0 \pm 1.8$ & $3.0 \pm 1.2$ & $1.1 \pm 0.4$ & $0.8 \pm 0.2$ \\
\hline ADP $\ddagger$ & $18.2 \pm 3.4$ & $11.1 \pm 2.8$ & $7.0 \pm 2.1$ & $3.7 \pm 2.7$ & $2.2 \pm 1.1$ \\
\hline Collagen ${ }^{8}$ & - & - & $\mathrm{ND}^{\prime \prime}$ & ND & ND \\
\hline
\end{tabular}

\footnotetext{
* Plasminogen-free bovine thrombin was added to platelet-rich plasma to a final concentration of $0.5 \mathrm{U} / \mathrm{ml}$ in the presence of $1 \mathrm{mM}$ GPRP to inhibit fibrin polymerization. t-PA was added $1 \mathrm{~min}$ after addition of thrombin, by which time the monophasic aggregation response reached a maximum value. Each point represents the mean \pm standard deviation of three experiments using three different donors, each done in duplicate. ${ }_{t} \mathrm{t}-\mathrm{PA}$ was added $1 \mathrm{~min}$ after addition of ADP (11 $\mu \mathrm{M}$ final concentration), by which time the monophasic aggregation response had reached a maximum value. Each point represents the mean \pm standard deviation of seven experiments using seven different donors, each done in duplicate. ${ }^{5}$ Aggregation was induced with $0.12 \mathrm{mg} / \mathrm{ml}$ calf skin collagen and t-PA added $30 \mathrm{~s}$ after the monophasic aggregation response reached a maximum value, which was approximately 2 min after collagen addition. "ND, No disaggregation detected.
}

aggregates to plasmin leads to their disaggregation (40). In contrast, two reports $(41,42)$ suggest that plasmin induces platelet aggregation. In these two studies, however, washed platelets were used in physiologic buffers rather than platelets in plasma. In the experiments presented here, the effect of human plasmin (produced from ambient plasma plasminogen by the action of recombinant human t-PA) on already formed human platelet aggregates was studied in plasma, making any attempts at direct comparison with earlier work $(41,42)$ unjustified.

The ability of t-PA to induce plasmin-mediated platelet disaggregation was found to be dependent on the concentration of t-PA used, as well as the time of its addition to the aggregated platelets. These observations, in addition to the observation that aspirin treatment of platelets markedly potentiated the disaggregating effects of t-PA, suggest that one possible explanation for this phenomenon is that after the induction of aggregation, platelets become progressively more resistant to disaggregation through one of several possible mechanisms. Either the development of the release reaction (43), progression to irreversible fibrinogen binding $(44,45)$, or both may be important determinants of the susceptibility of platelets to disaggregation induced by t-PA in plasma. Another explanation for the effect of aspirin in this system is that aspirin inhibits the use of arachidonate released by plasmins' action on platelets (46). Further studies will be needed to clarify unequivocally the mechanistic determinants of this phenomenon.

Whether the phenomenon of platelet disaggregation induced by t-PA has any relevance to human pathophysiology or pharmacology has yet to be determined. Clearly, using ADP-induced platelet aggregation in platelet-rich plasma as a model for in vivo platelet thrombus formation, pharmacologically achievable concentrations (29) of t-PA can result in aggregate dispersal. Whether local concentrations of t-PA secreted by endothelial cells can produce the same effect on small, transiently formed platelet aggregates is not known.

Disaggregation of platelets has been considered by some investigators (47-51) as an important in vitro measure of the efficacy of antiplatelet agents. The mechanism by which agents that disaggregate platelets act depends upon the specific disaggregant and the agonist used. As Rao and White demonstrated (51), disaggregating ability is selective and depends on the time of addition of disaggregant. In addition, these authors showed that some agents that inhibit aggregation can cause disaggrega- tion, but not all of the agents studied could do so. Finally, they showed that once dissociated, disaggregated platelets were refractory to further addition of agonist, regardless of the agent used.

We have demonstrated that the disaggregation of platelets induced by t-PA in plasma is a direct consequence of plasminogen activation and the action of plasmin on the platelet aggregate. Aggregates produced by the addition of the fibrinogen-dependent agonists, ADP and thrombin, were susceptible to disaggregation by t-PA. Aggregates produced by collagen were resistant to disaggregation by t-PA, probably because platelets aggregate in response to collagen by fibrinogen-independent, as well as fibrinogen-dependent, mechanisms (52), and because platelets adhere to collagen fibrils early in the aggregation process and can undergo secretion before aggregation (53), thereby producing aggregates of different gross morphology containing platelets in different phases of (irreversible) release than with other fibrinogen-dependent agonists.

Disaggregation induced by t-PA was reversible with addition of fresh platelet-poor plasma or of purified human fibrinogen, and disaggregation was accompanied by a kinetically selective loss of cohesive fibrinogen without a detectable effect of plasmin under these conditions on platelet fibrinogen receptors (corroborated by the data of Peerschke and colleagues [45]). These data suggest that t-PA disperses platelet aggregates formed by fibrinogen-dependent agonists through the selective fibrinogenolysis by plasmin of platelet-bound fibrinogen. Whether t-PA has a specific affinity for platelet-bound cohesive fibrinogen similar to that for fibrin, rather than that for unbound fibrinogen, has yet to be determined. In addition, plasmin formed in the platelet aggregate may have effects on other important adhesive proteins, such as thrombospondin and von Willebrand protein, that have yet to be determined; however, the experiments performed in the washed platelet system in which purified fibrinogen restores aggregation argues that in this system fibrinogen alone is the crucial plasmin substrate, the proteolysis of which led to disaggregation.

Miles and Plow $(10,54)$ have clearly demonstrated that platelets bind plasminogen and that this binding enhances conversion to plasmin by urokinase, streptokinase, and t-PA. Platelet activation by thrombin was found to stimulate plasminogen binding three- to ninefold above that observed with resting platelets. These authors concluded that the binding of plasmin- 
ogen to the platelet surface localizes and promotes activation of plasminogen and consequent fibrinolysis at an important site of fibrin formation. In the context of these data, our data suggest that plasminogen activation on the platelet surface by t-PA is also important for fibrinogenolysis of platelet-bound, cohesive fibrinogen, and that this mechanism is responsible for the disaggregation of platelets that are maintained as aggregates by fibrinogen. This mechanism may be important in vivo both as a local vascular mechanism for reversing (transient) platelet aggregation as well as a generalized mechanism for promoting the lysis of thrombi containing both platelets and fibrin.

\section{Acknowledgments}

The authors wish to thank Dimitry Rabkin, Jan Kim, and Irina BarskyVasserman for excellent technical assistance, Drs. Andrew Schafer and Robert Handin for helpful discussion, and Dr. Henry Slayter for performing the thrombospondin assay.

This work was supported in part by a Grant-in-Aid from the Massachusetts affiliate of the American Heart Association and in part by National Institute of Health grants HL-17153 and HL-07049. Dr. Loscalzo is the recipient of a Clinician-Scientist Award from the American Heart Association.

\section{References}

1. Astrup, T., and P. M. Permin. 1947. Fibrinolysis in the animal organism. Nature (Lond.). 159:681-682.

2. Astrup, T. 1966. Tissue activators of plasminogen. Fed. Proc. 25: $42-51$.

3. Wiman, B., and D. Collen. 1978. Molecular mechanisms of physiologic fibrinolysis. Nature (Lond.). 272:549-550.

4. Rijken, D. C., G. Wigngaards, M. Zaal-de Jong, and J. Welbergen. 1979. Purification and partial characterization of plasminogen activator from human uterine tissue. Biochim. Biophys. Acta. 580:140-153.

5. Collen, D., J. M. Stassen, B. J. Marafino, Jr., S. Builder, F. de Cock, J. Ogez, D. Tajeri, D. Pennica, W. F. Bennett, J. Saliva, and C. F. Hoyng. 1984. Biological properties of human tissue-type plasminogen activator obtained by expression of recombinant DNA in mammalian cells. J. Pharmacol. Exp. Ther. 231:146-152.

6. Hoylaerts, M., D. C. Rijken, H. R. Lignen, and D. Collen. 1982. Kinetics of the activation of plasminogen by human tissue plasminogen activator. J. Biol. Chem. 257:2912-2919.

7. Stricker, R. B., D. Wong, D. T. Shin, P. Lysenko, and M. A. Shuman. 1986. Activation of plasminogen by tissue plasminogen activator on normal and thrombasthenic platelets: effect of surface proteins and platelet aggregation. Blood. 68:275-280.

8. Adelman, B., A. D. Michelson, J. Loscalzo, J. Greenberg, and R. I. Handin. 1985. Plasmin effect on platelet glycoprotein Ib-von Willebrand factor interactions. Blood. 65:32-40.

9. Schafer, A. I., and B. Adelman. 1985. Plasmin inhibition of platelet function and arachidonic acid metabolism. J. Clin. Invest. 75:456-461.

10. Miles, L. A., and E. F. Plow. 1985. Binding and activation of plasminogen on the platelet surface. J. Biol. Chem. 260:4303-4311.

11. Haerem, J. W. 1972. Platelet aggregates in intramyocardial vessels of patients dying suddenly and unexpectedly from coronary artery disease. Atherosclerosis. 15:199-213.

12. Haerem, J. W. 1974. Mural platelet microthrombi and major acute lesions of main epicardial arteries in sudden cardiac death. Ath erosclerosis. 19:529-541.

13. Falk, E. 1985. Unstable angina with fatal outcome: dynamic coronary thrombosis leading to infarction or sudden death. Circulation. 71:699-708.

14. Willerson, J. T., W. B. Campbell, M. D. Winniford, J. Schmitz, P. Apprill, B. G. Firth, J. Ashton, T. Smitherman, L. Bush, and L. M. Buja. 1984. Conversion from chronic to acute coronary artery disease: speculations regarding mechanism. Am. J. Cardiol. 54:1349-1354.
15. Davies, M. J., A. C. Thomas, P. A. Knapman, and J. R. Hangartner. 1986. Intramyocardial platelet aggregation in patients with unstable angina suffering sudden ischemic cardiac death. Circulation. 73: 418-427.

16. Born, G. V. R., and M. J. Cross. 1963. The aggregation of blood platelets. J. Physiol. (Lond.). 168:178-195.

17. Phillips, D. R. 1972. Effect of trypsin on the exposed polypeptides and glycoproteins in the human platelet membrane. Biochemistry. 11: 4582-4588.

18. Nachman, R. L., A. Hubbard, and B. Ferris. 1973. Iodination of human platelet membranes. J. Biol. Chem. 248:2928-2936.

19. Bennett, J. S., and G. Vilaire. 1979. Exposure of platelet fibrinogen receptors by ADP and epinephrine. J. Clin. Invest. 64:1393-1401.

20. Loscalzo, J., A. Inbal, and R. I. Handin. 1986. Von Willebrand protein facilitates platelet incorporation in polymerizing fibrin. J. Clin. Invest. 78:1112-1119.

21. Peerschke, E. I. B. 1985. The platelet fibrinogen receptor. Semin. Hematol. 22:241-259.

22. Rampling, M. W., and P. J. Gaffney. 1976. The sulphite precipitation method for fibrinogen measurement: its use on small samples in the presence of fibrinogen degradation products. Clin. Chim. Acta. 67: 43-52.

23. Merskey, C., G. J. Kleiner, and A. J. Johnson. 1966. Quantitative estimation of split products of fibrinogen in human serum: relation to diagnosis and treatment. Blood. 28:1-8.

24. Merskey, C., P. Lalezari, and A. J. Johnson. 1969. A rapid simple sensitive method for measuring fibrinolytic split products in human serum. Proc. Soc. Exp. Biol. Med. 131:871-878.

25. Teger-Nilsson, A. C., P. Friberger, and E. Gyzander. 1977. Determination of a new rapid plasmin inhibitor in human blood by means of a plasma specific tripeptide substrate. Scand. J. Clin. Lab. Invest. 37: 403-409.

26. Friberger, P., M. Knos, S. Gustavsson, L. Aurell, and G. Claeson. 1978. Methods for determination of plasmin, antiplasmin, and plasminogen by means of substrate S-2251. Haemostasis. 7:138-145.

27. Laemmli, U. K. 1970. Cleavage of structural proteins during assembly of the head of bacteriophage T4. Nature (Lond.). 227:680-682.

28. Lowry, O. H., N. J. Rosebrough, A. L. Farr, and R. J. Randall. 1950. Protein measurement with the Folin phenol reagent. J. Biol. Chem. 193:265-275.

29. Gold, H. K., R. C. Leinbach, H. D. Garabedian, T. Yasuda, J. A. Johns, E. B. Grossbard, I. Palacios, and D. Collen. 1986. Acute coronary reocclusion after thrombolysis with recombinant human tissuetype plasminogen activator: prevention by maintenance infusion. Circulation. 73:347-352.

30. Scatchard, G. 1949. An analysis of ligand binding to macromolecules. Ann. NY Acad. Sci. 51:660-672.

31. Tandon, N., J. T. Harmon, D. Rodbard, and G. A. Jamieson. 1983. Thrombin receptors define responsiveness of cholesterol-modified platelets. J. Biol. Chem. 258:11840-11845.

32. Mehta, P., and J. Mehta. 1977. Platelet function studies in coronary artery disease. V. Evidence for enhanced platelet microthrombus formation activity in acute myocardial infarction. Am. J. Cardiol. 43: 757-760.

33. Doughtery, J. H., D. E. Levy, and B. B. Weksler. 1977. Platelet activation in acute cerebral ischemia. Lancet. i:821-824.

34. Lowe, G. D. O., M. M. Reavey, R. V. Johnston, C. D. Forbes, and C. R. M. Prentice. 1979. Increased platelet aggregates in vascular and nonvascular illness: correlation with plasma fibrinogen and effect of ancrod. Thromb. Res. 14:377-386.

35. Wu, K. K., R. W. Barnes, and J. C. Hoak. 1976. Platelet hyperaggregability in idiopathic recurrent deep venous thrombosis. Circulation. 53:687-691.

36. Wu, K. K., and J. C. Hoak. 1974. A new method for quantitative detection of platelet aggregates in patients with arterial insufficiency. Lancet. ii:924-926.

37. Bowry, S. K., C. R. M. Prentice, and J. M. Courtney. 1985. A 
modification of the $\mathrm{Wu}$ and Hoak method for detection of platelet aggregates and platelet adhesion. Thromb. Haemostas. 53:381-385.

38. Prazich, J. A., S. I. Rapaport, J. R. Samples, and R. Engler. 1977. Platelet aggregate ratios: standardization, technique and test results in patients with myocardial ischemia and patients with cerebrovascular disease. Thromb. Haemostasis. 38:597-605.

39. Kohanna, F. H., M. A. Smith, and E. W. Salzman. 1984. Do patients with thromboembolic disease have circulating platelet aggregates? Blood. 64:205-209.

40. Miller, J. L., A. J. Katz, and M. B. Feinstein. 1975. Plasmin inhibition of thrombin-induced platelet aggregation. Thromb. Diath. Haemorrh. 33:286-309.

41. Niewiarowski, S., A. F. Senyi, and P. Gillies. 1973. Plasmininduced platelet aggregation and platelet release reaction. J. Clin. Invest. 52:1647-1659.

42. Guccione, M. A., R. L. Kinlough-Rathbone, M. A. Packham, E. J. Harfenist, M. L. Rand, J. P. Greenberg, D. W. Perry, and J. F. Mustard. 1985. Effect of plasmin on rabbit platelets. Thromb. Haemostasis. 53:8-14.

43. Holmsen, H., L. Salganicoff, and M. M. Fukami. 1977. Platelet secretion. In Haemostasis: Biochemistry, Physiology and Pathology. D. Ogston and B. Bennett, editors. John Wiley \& Sons Inc., New York. 241-319.

44. Marguerie, G. A., T. S. Edgington, and E. F. Plow. 1980. Interaction of fibrinogen with its platelet receptor as part of a multistep reaction in ADP-induced platelet aggregation. J. Biol. Chem. 255:154-161.

45. Peerschke, E. I. B., and J. A. Wainer. 1985. Examination of irreversible platelet-fibrinogen interactions. Am. J. Physiol. 248:C466C472.

46. Schafer, A. I., A. K. Maas, A. Ware, P. C. Johnson, S. E. Ritten- house, and E. W. Salzman. 1986. Platelet protein phosphorylation, elevation of cytosolic calcium, and inositol phospholipid breakdown in platelet activation induced by plasmin. J. Clin. Invest. 78:73-79.

47. Rao, G. H. R., K. R. Reddy, and J. G. White. 1980. The influence of epinephrine on prostacyclin $\left(\mathrm{PGI}_{2}\right)$ induced dissociation of ADP aggregated platelets. Prost. \& Med. 4:385-397.

48. LeBreton, G. C., and D. L. Venton. 1980. Thromboxane $A_{2}$ receptor antagonist selectively reverses platelet aggregation. Adv. Prostaglandin Thromboxe Res. 6:497-503.

49. Rodomski, M., J. Swies, and R. J. Gryglewski. 1981. Disaggregatory action of phosphodiesterase inhibitors. Pharmacol. Res. Commun. $13: 41-47$

50. Kinlough-Rathbone, R. L., J. F. Mustard, D. W. Perry, E. Dejana, J.-P. Cazenave, M. A. Packham, and E. J. Harfenist. 1983. Factors influencing the deaggregation of human and rabbit platelets. Thromb. Haemostasis. 49:162-167.

51. Rao, G. H. R., and J. G. White. 1985. Disaggregation and reaggregation of 'irreversibly' aggregated platelets: a method for more complete evaluation of anti-platelet drugs. Agents Actions. 16:425-434.

52. Connellan, J. M., P. J. Thurlow, B. Barlow, M. Lowe, and I. F. C. McKenzie. 1986. Investigation of alternative mechanisms of collagen-induced platelet activation by using monoclonal antibodies to glycoprotein IIb-IIIa and fibrinogen. Thromb. Haemostasis. 55:153-157.

53. Marcus, A. J. 1982. Platelet aggregation. In Hemostasis and Thrombosis. R. W. Colman, J. Hirsh, V. J. Marder, and E. W. Salzman, editors. J. B. Lippincott, Co., Philadelphia. 385.

54. Miles, L. A., M. H. Ginsberg, J. G. White, and E. F. Plow. 1986. Plasminogen interacts with human platelets through two distinct mechanisms. J. Biol. Chem. 77:2001-2009. 